\title{
Gynecological and psycho-sexual aspects of women with history of anorectal malformations
}

\author{
Noemi Bicelli ${ }^{1,3} \cdot$ Emanuele Trovalusci $^{1,3} \cdot$ Monica Zannol $^{2} \cdot$ Piergiorgio Gamba $^{3} \cdot$ Gianna Bogana $^{4} \cdot$ Cinzia Zanatta $^{1}$. \\ Paola Midrio ${ }^{1,3}$ (1)
}

Accepted: 31 March 2021 / Published online: 26 April 2021

(c) The Author(s) 2021

\begin{abstract}
Purpose Women with anorectal malformation (ARM) are expected to have a normal life span, therefore, gynecological and psycho-sexual issues are also important. Aim of the study was to assess these aspects in adult females with history of ARM. Methods Thirty-seven women from two ARM referral centers, aged $\geq 16$, were identified. Gynecologic visit, cervicovaginal swab, pelvic ultrasound, FSH, LH, prolactin, progesterone, $17-\beta$-estradiol, DHEAS, testosterone, TSH during follicular and luteal phases, and administration of FSFI questionnaire to screen the female sexual functioning were performed. Data were compared with six controls.

Results Nineteen patients, mean age 21.7 (16-45), participated to the study. Associated anomalies, mostly affecting limbs, vertebrae and genitalia, were present in $57.8 \%$ of cases. Mullerian anomalies were retrieved in $36.8 \%$. Hormones' levels were normal. Concerning sexual functioning, four women (21\%) reported dyspareunia or impossible penetration, four did not answer the FSFI questionnaire due to lack of confidence about their sexuality, and three scored lower than the cut-off value for female sexual function.

Conclusion This study confirms the importance of a multidisciplinary long-term follow-up for ARM patients, including a careful study of the reproductive tract to detect and treat those conditions that could affect the fertility. Moreover, an appropriate psychological support should be provided.
\end{abstract}

Keywords Anorectal malformation $\cdot$ Adult life $\cdot$ Gynecological aspects $\cdot$ Sexuality $\cdot$ Psychological well-being

\section{Introduction}

The anorectal malformations (ARM) are rare congenital anomalies affecting the distal gastrointestinal tract. They occur in one in 2500-5000 live births and encompass a spectrum of types, from the simplest cases with an expected good outcome to the rarest and most complex situations with poor functional outcome [1]. In females, the most common ARM is the rectoperineal fistula [2], followed by the rectovestibular fistula and then the cloaca. $50-80 \%$ of ARM patients have at least one other congenital malformation,

Paola Midrio

paola.midrio@unipd.it

Pediatric Surgery, Cà Foncello Hospital, Treviso, Italy

Obstetrics\&Gynecology, Cà Foncello Hospital, Treviso, Italy

Pediatric Surgery, Università Di Padova, Padova, Italy

4 Obstetrics\&Gynecology, Azienda Ospedaliera, Padova, Italy affecting the genitourinary, cardiac, skeletal, and spinal apparati. The posterior sagittal anorectoplasty (PSARP) is the most common surgical technique performed to correct ARM [1]. A life-long multidisciplinary follow-up is suggested world-wide to optimize the outcome and timely manage the complications.

Female patients born with ARM are expected to have a normal life span, therefore, gynecological and psycho-sexual issues become important aspects of their adult life.

This study aimed to assess these aspects in adult females with history of ARM, to investigate the function of their genital system, the reproductive potential, and how the presence of an ARM influenced the sexual well-being. 


\section{Materials and methods}

\section{Population}

A multifactorial evaluation of adult female patients with history of ARM was performed. Female patients aged $\geq 16$ followed-up at two Italian referral centers (Treviso and Padua) were retrieved for the study. Exclusion criteria were age $>45$ (perimenopause stage), previous deliveries, and severe mental retardation. Data were compared with a total of six healthy controls, chosen with the same criteria and with mean age of 26.8 years (22-30 years). All participants provided written informed consent.

\section{Medical, gynecological, and sexual history}

The complete medical, gynecological, sexual and familiar history, including the presence of relatives affected by ARM, were collected for each patient. Moreover, the type of original malformation, comorbidities, surgical procedures and complications, bowel management, genitourinary disorders, menarche onset, and characteristics of menstrual periods were examined. Finally, some aspects of sexual activity, such as age of their first intercourse, presence of dyspareunia, vaginismus, infections, and results of previous Pap-tests, were investigated.

\section{Gynecologic examination, pelvic ultrasound, and cervicovaginal swab}

All patients underwent a complete gynecologic examination to assess the development of secondary sexual characters, genitalia and breast. The Body Mass Index (BMI) was calculated, and secondary sexual characters were described. A pelvic ultrasound was performed to evaluate the internal genital organs. Whenever possible, speculum examination and endovaginal ultrasound were performed to obtain further information. Size and number of uterus, ovaries, endometrium, and Fallopian tubes were described. Cervicovaginal samples were collected to detect ecto- and endocervical microorganisms, such as Streptococcus, Gardnerella vaginalis, Trichomonas vaginalis, Neisseria gonorrhoeae, Chlamydia trachomatis, Mycoplasma, and Ureaplasma.

\section{Hormones}

Each patient underwent two blood samples to dose the female sexual hormones. The first sample was taken between the 3rd and 5th day of menstrual cycle (follicular phase) to dose FSH, LH, prolactin, progesterone, $17-\beta$-estradiol, DHEAS, testosterone, and TSH. The second sample was taken between the 20th and 22nd day of cycle (luteal phase) to dose the progesterone.

\section{Psycho-sexual FSFI-questionnaire}

The FSFI questionnaire (Female Sexual Function Index) was administered. The FSFI is a very diffuse tool to screen the female sexual dysfunction [3], composed by 19-item selfreported tool, with six domains, scored on a scale from 0 (or 1) to 5: desire, arousal, lubrification, satisfaction, orgasm, and pain (Table 1). A total score of 26.55 is the cut-off to differentiate women with or without sexual dysfunction [4]. The validated Italian version was used in this study [5].

\section{Statistics}

Data were expressed as mean \pm standard deviation. Student's t test was used. Statistical significance level was set at $p<0.05$.

\section{Results}

A total of 37 consecutive women were eligible for the study and, among these, 19 (52\%) patients agreed to participate in the study, 12 (32\%) could not reach the referral centers to attend the medical appointments, and $6(16 \%)$ were not interested. The mean age of participants was 21.7 years (16-31 years). According to the Krickenbeck classification, patients were affected by cloaca (seven cases), rectovestibular fistula (six cases), imperforate anus without fistula (two cases), perineal fistula (two cases), and one each by rectovaginal fistula and non-specified low type. Eighteen patients underwent PSARP or posterior sagittal anorecto-vagino-urethroplasty (PSARVUP) during infancy; one patient born with rectovestibular fistula required surgical repair at the age of 22 years.

Ten women reported to have a good bowel management by means of diet and nine by means of trans-anal irrigation (two of them use simple enemas and seven use Peristeen ${ }^{\circledR}$ bowel irrigation system). On the other hand, the most

Table 1 Score system for the Female Sexual Function Index (FSFI)

\begin{tabular}{llll}
\hline Domain & Score Range & $\begin{array}{l}\text { Minimum } \\
\text { Score }\end{array}$ & $\begin{array}{l}\text { Maxi- } \\
\text { mum } \\
\text { Score }\end{array}$ \\
\hline Desire & $1-5$ & 2 & 10 \\
Arousal & $0-5$ & 0 & 20 \\
Lubrication & $0-5$ & 0 & 20 \\
Orgasm & $0-5$ & 0 & 15 \\
Satisfaction & $1-5$ & 2 & 15 \\
Pain & $0-5$ & 0 & 15 \\
\hline
\end{tabular}


common urinary problems were recurrent urinary infections (five cases, three of them practice the intermittent catheterization).

Associated anomalies were present in 11 cases (57.8\%) with a combination of affected organs: skeletal system (six cases), heart (five cases), urinary system (five cases), esophagus (two cases), filum terminale lipoma (two cases), tethered cord (one case), laryngeal schisis (one case), and PruneBelly Syndrome (one case). Malformations regarding the genital system were present in in $36.8 \%$ (seven cases-four of them cloaca patients): three absence of uterus, two uterine septa and one each with uterus didelphys and bicornuate unicollis. Moreover, seven patients (36.8\%-five of them cloaca) presented anomalies of the vagina: three stenotic and short vagina (three cloaca), and four vaginal agenesia (two cloaca and two rectovestibular fistula). Vaginal reconstruction was performed during the PSARVUP procedure in four cloaca patients, while in the other cases vaginoplasty was performed with colon (three patients), ileum (one patient), and Fortunoff flap (one patient). The gynecological examination revealed good outcome in all these patients, apart from two of them treated with PSARVUP and not yet sexually active, who showed a $2 \mathrm{~cm}$ vagina and an introital stenosis, respectively (Table 2).

The mean age of menarche was 12.3 (11-15 years). Ten women reported mild dysmenorrhea and one severe, and five oligomenorrhea. At the time of the study five women were taking oral contraceptives.

Hormones' levels were normal in our population and there was no significant difference between patients and controls (Fig. 1). Only LH levels were significantly different (4.75 UI/L vs $8.71, p=0.04)$, but still within the normal values.

Pathogenic microorganisms were not isolated in any of our patients.

Concerning sexual aspects, nine women (47\%) were sexually active but four reported at least one episode of discomfort during penetration. In particular one patient with rectovaginal fistula described visceral pain during the intercourse and another one with cloaca was affected by dyspareunia and anorgasmia associated to a short and stenotic vagina. Three women of this group scored below the cut-off of 26.55 at FSFI questionnaire, proving an objective sexual dysfunction. Among the other 11 women (53\%), four patients did not answer the FSFI questionnaire due to lack of confidence about their sexuality, the others scored under the cut-off. It is worth mentioning that a patient, born with perineal fistula, is unable to have intercourse due to severe pain during any attempt of penetration; no anatomical anomalies were detected during her gynecological examination but only vaginism and pelvic floor muscle hypertonia.

None of our patients had planned a pregnancy yet.

\section{Discussion}

ARM patients are often complex patients who need a life-long multidisciplinary follow-up after surgical reconstruction. For this study, female patients aged $\geq 16$ were enrolled to assess both their hypothalamic-pituitary-gonad axis and sexual life. The distribution of different ARM types among our patients showed an exceptional high percentage of patients born with cloaca and this explains the high incidence of associated anomalies. The patients were, indeed, enrolled from two national reference centers for ARM where more complex cases are treated.

The literature about female fertility among ARM patients is scarce because some authors describe just the gynecologic anomalies [6], some others assess their general quality of life including sexual well-being [7-9], or they report on fertility without considering the gynecologic or psychological assessment [10]. Female fertility is defined as the capacity to conceive and to produce offspring after a year of unprotected intercourse. A recent meta-analysis [10] tried to assess ARM patients' fertility with childbirth rate as criterion, observing no statistical difference between males and females (15\% vs $19 \%$, respectively; $p=0.45 \%$ ). On the contrary, this rate became significant in female population when less and complex ARM were compared ( $39 \%$ vs $14 \% ; p=0.04$ ). This evidence suggests that, besides the correlation between severity of genital malformations and type of ARM [11], the psychosocial aspects related to the medical condition could have a higher impact in female patients. None of our patients had planned a pregnancy yet, probably because of the young age of participants (mean age 21.68 years), that is quite lower than the mean age of Italian women first pregnancy (31.9 years) [12].

Mullerian anomalies are widely represented among ARM patients $(30 \%)$, in contrast to their incidence in general population (2-4\%) [13]. In our sample more than half of women $(52.6 \%)$ had genital abnormalities, including mild and severe, congenital and acquired. In this study, just a firstline gynecological investigation was performed but some authors suggest that also the pelvic MRI should be part of the gynecological follow-up [14]. The pregnancy is still possible in case of Mullerian anomalies, however, a worse obstetrical outcome, in terms of miscarriages and preterm labor, needs to be anticipated and cared for at specialized centers. In general, pregnancies in ARM patients must be considered as "high-risk pregnancies" and possibly referred to a center where a pediatric surgeon expert of these types of malformations is present. For most of the cases a C/section is advised to avoid overstretching and damages to the repaired pelvic floor and sphincters [15]. 


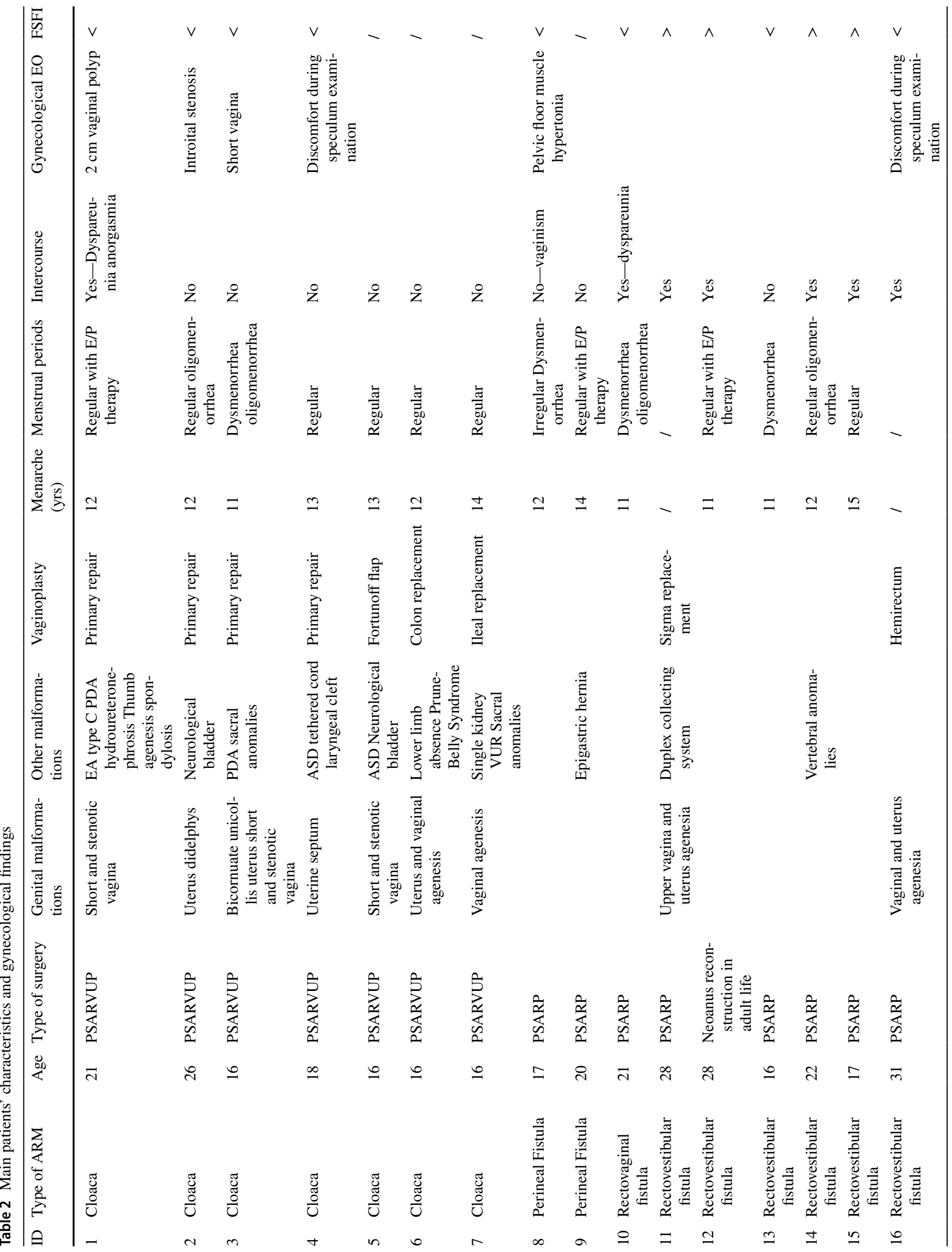


Despite the high percentage of associated genital malformations, patients' sexual hormones levels were found normal and comparable to those measured in controls; same for the mean menarche age, which is consistent with the female Italian population (12.3 vs 12.4 years) [16]. That's not unusual, in fact the hypothalamus-pituitary-ovarian axes is normally functioning in ARM patients, even in those with cloaca-who normally show more complex genital anomalies-because ovaries have a different embryological origin compared to urogenital and anorectal tracts. [17]

Vaginoplasty is normally performed in patients born with cloaca or urogenital sinus, but could be required also in rectovestibular fistula, considering that vaginal agenesia is associated in $9.5-16.3 \%$ [18]. Primary reconstruction is less invasive and more natural, but the vagina could shrink during childhood, as dilatations are not indicated and there is no hormonal stimulation at this age. On the contrary, different vaginoplasty techniques are described, the most frequently being with a tract of sigma or colon. The advantages are the possibility to achieve a good length, size, and lubrification to allow a normal sexual activity, even though the reduced fecal reservoir may favor some degree of incontinence. [19]

Sexual well-being in ARM patients is indeterminate and, often, compromised by both anatomical and psychological problems. The presence of malformed systems and related consequences, such as fecal or urinary incontinence, could affect the quality of life, self-esteem, and sexual well-being [7, 20, 21]. Recently, Eleuteri S. et al. [21] observed that the most frequent problems during sexual intercourse in female patients are loss of feces, pain and lack of vaginal lubrification. These problems are rarely discussed with the pediatric surgeons or other ARM specialists who, indeed, seem not enough confident nor competent to treat these aspects. However, the sexual wellbeing is considered so important that it has been recommended to address it in a multidisciplinary program [22]. About our experience, some patients referred they stopped having intercourse because of pelvic pain or vaginismus that, eventually, compromised their relationship. In some cases, a stenotic and short vaginal canal that impeded a complete gynecological examination was detected and for these women a reconstructive vaginoplasty was recommended. Three sexually active women complained dyspareunia for which a psycho-sexologist was suggested.

\section{Conclusions}

One of the challenges in the care of ARM patients is the correct transition from the pediatric to the adult life to guarantee the same multidisciplinary follow-up they received during 
$\mathrm{FSH}$

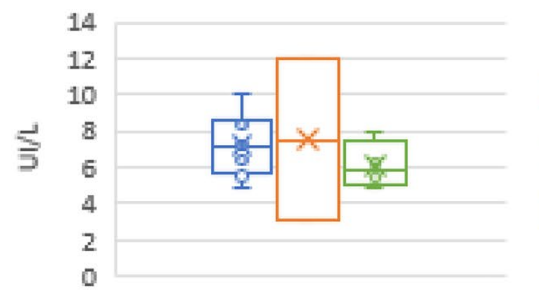

Prolactin

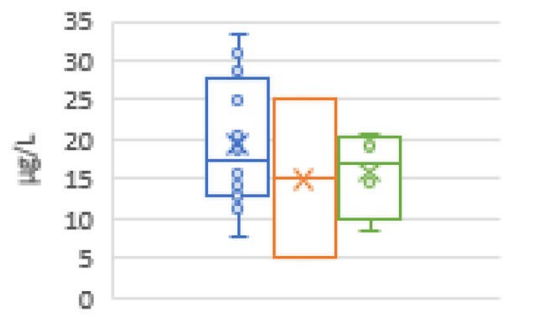

ARM

$\square$ Lab

$\square$ Controls

$p=0,35$

\section{Progesterone (follicular phase)}

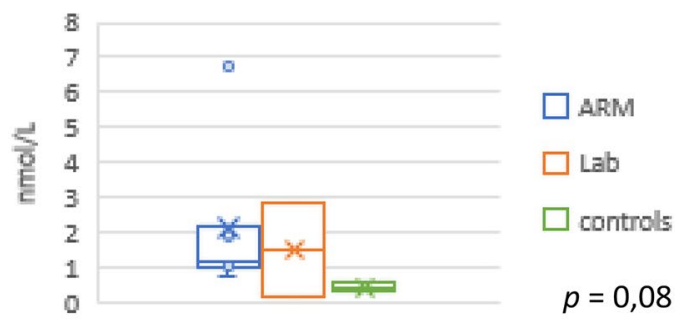

LH

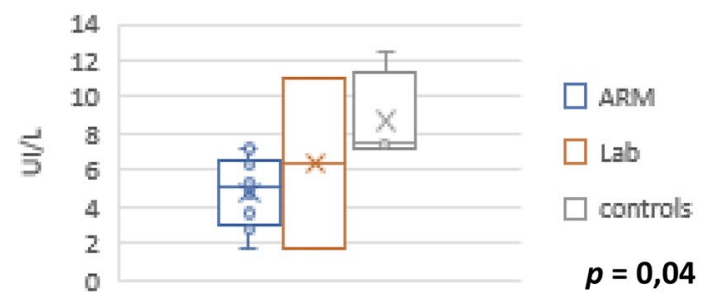

\section{7- $\beta$-ESTRADIOL}

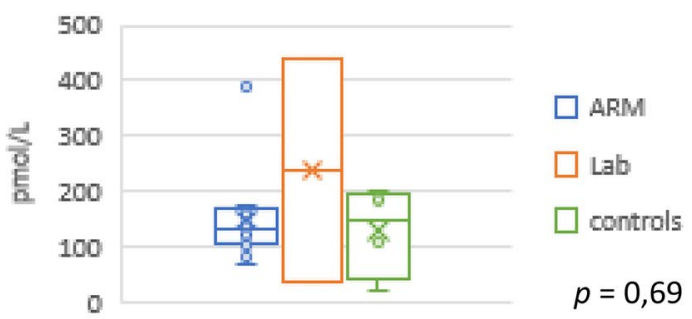

\section{Progesterone (luteal phase)}

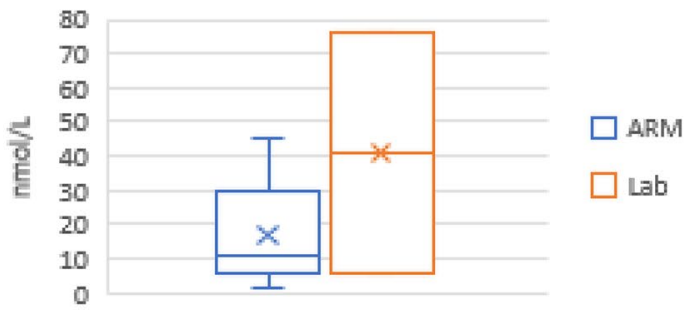

Fig. 1 Comparison of female hormone levels in ARM cases, controls and laboratory values

childhood [23]. This study confirms, indeed, the importance of a multidisciplinary long-term follow-up, that, in case of women, should include also the gynecologist, the pelvic floor trainer, and the psycho-sexologist.

Funding Open access funding provided by Università degli Studi di Padova within the CRUI-CARE Agreement. The authors received no financial support for the research, authorship, and/or publication of this article.

\section{Declarations}

Conflicts of interest The authors declare that they have no conflict of interest or financial ties to disclose.

Ethics approval All procedures performed in studies involving human participants were in accordance with the ethical standards of the institutional and/or national research committee and with the 1964 Helsinki declaration and its later amendments or comparable ethical standards.
Consent to participate Informed consent was obtained from all individual participants included in the study.

Open Access This article is licensed under a Creative Commons Attribution 4.0 International License, which permits use, sharing, adaptation, distribution and reproduction in any medium or format, as long as you give appropriate credit to the original author(s) and the source, provide a link to the Creative Commons licence, and indicate if changes were made. The images or other third party material in this article are included in the article's Creative Commons licence, unless indicated otherwise in a credit line to the material. If material is not included in the article's Creative Commons licence and your intended use is not permitted by statutory regulation or exceeds the permitted use, you will need to obtain permission directly from the copyright holder. To view a copy of this licence, visit http://creativecommons.org/licenses/by/4.0/.

\section{References}

1. Holschneider A, Hutson J, Peña A, Beket E (2005) Preliminary report on the International Conference for the Development of Standards for the Treatment of Anorectal Malformations. J Pediatr Surg 40:1521-1526 
2. Jenetzky E, van Rooij I, Aminoff D et al (2015) The challenges of the European anorectal malformations-net registry. Eur J Pediatr Surg 25:481-487

3. Meston C (2003) Validation of the Female Sexual Function Index (FSFI) in women with female orgasmic disorder and in women with hypoactive sexual desire disorder. J Sex Marital Ther 29:39-46

4. Wiegel M, Meston C, Rosen R (2005) The Female Sexual Function Index (FSFI): Cross-validation and development of clinical cut-off scores. J Sex Marital Ther 31:1-20

5. Filocamo MT, Serati M, Li Marzi V et al (2014) The Female Sexual Function Index (FSFI): linguistic validation of the Italian version. J Sex Med 11:447-453

6. Vilanova-Sanchez A, Reck CA, McCracken KA et al (2018) Gynecologic anatomic abnormalities following anorectal malformations repair. J Pediatr Surg 53(4):698-703

7. Davies MC, Liao L, Wilcox DT, Woodhouse CRJ, Creighton SM (2010) Anorectal malformations: what happens in adulthood? BJU Int 106(3):398-404

8. Schmidt D, Winter S, Jenetzky E, Zwink N, Schmiedeke E, Maerzheuser S (2012) Sexual function in adults with anorectal malformation: psychosocial adaptation. German Network for Congenital Uro-REctal Malformations (CURE-Net). Pediatr Surg Int 28(8):789-792

9. Van den Hondel D, Sloots CEJ, Bolt JM, Wijnen RMH, de Blaauw I, Ijsselstijn H (2015) Psychosexual well-being after childhood surgery for anorectal malformation or Hirschsprung's disease. J Sex Med. 12(7):1616-1625

10. Huibregtse ECP, Draaisma JMT, Hofmeester MJ, Kluivers K, van Rooij IALM, de Blaauw I (2014) The influence of anorectal malformations on fertility: a systematic review. Pediatr Surg Int 30(8):773-781

11. Nah SA, Ong CC, Lakshmi NK, Yap TL, Jacobsen AS, Low Y (2012) Anomalies associated with anorectal malformations according to the Krickenbeck anatomic classification. J Pediatr Surg 47(12):2273-2278

12. ISTAT. Indicatori Demografici anno 2019. Centro Diffusione Dati, Italia: 2020.

13. Rackow BW, Arici A (2007) Reproductive performance of women with Mullerian anomalies. Curr Opin Obstet Gynecol 19(3):229-237

14. Fanjul M, Lancharro A, Molina E, Cerdà J (2019) Gynecological anomalies in patients with anorectal malformations. Pediatr Surg Int 35:967-970

15. Kyrklund K, Pakarinen MP, Rintala RJ (2017) Long-term bowel function, quality of life and sexual function in patients with anorectal malformations treated during the PSARP era. Semin Pediatr Surg 26(5):336-342

16. Rigon F, Bianchin L, Bernasconi S, Bona G, Bozzola M, Buzi F, Cicognani A, De Sanctis C, De Sanctis V, Radetti G, Tatò L, Tonini G, Perissinotto E (2010) Update on age at menarche in Italy: toward the leveling off of the secular trend. J Adolesc Health 46(3):238-244. https://doi.org/10.1016/j.jadohealth.2009.07.009

17. Pradhan S, Vilanova-Sanchez A, McCracken KA, Reck CA, Halleran DR, Wood RJ, Levitt M, Hewitt GD (2018) The Mullerian Black Box: Predicting and defining Mullerian anatomy in patients with cloacal abnormalities and the need for longitudinal assessment. J Pediatr Surg 53(11):2164-2169. https://doi.org/10.1016/j. jpedsurg.2018.05.009

18. De la Torre L, Cogley K, Calisto JL, Santos K, Ruiz A, Zornoza M (2016) Vaginal agenesis and rectovestibular fistula. Experience utilizing distal ileum for the vaginal replacement in these patients, preserving the natural fecal reservoir. J Pediatr Surg. 51(11):1871-1876. https://doi.org/10.1016/j.jpedsurg.2016.08. 003

19. Couchman A, Creighton SM, Wood D (2015) Adolescent and adult outcomes in women following childhood vaginal reconstruction for cloacal anomaly. J Urol 193(5 Suppl):1819-1822. https:// doi.org/10.1016/j.juro.2014.10.112

20. Grano C, Bucci S, Aminoff D, Lucidi F, Violani C (2014) Feelings of depression in people with arm: the role of critical incidents and perceived difficulties in close and sexual relationships. Pediatr Surg Int 30:823-828

21. Eleuteri S, Aminoff D, Lucidi F, Violani C, Grano C (2019) Sexual well-being in adolescent and young adults born with arm: the perspective of the patients. Ped Surg Int 35:945-951

22. Amerstorfer G, Verhaak G-V, Miserez R-S, Schwarzer H (2019) de Blaauw, Jenetzky, van der Steeg, van Rooij,ARM-Net Consortium, What do pediatric surgeons think about sexual issues in dealing with patients with anorectal malformations? ARM-Net Consortium members opinion Pediatr Surg Int 35:935-943

23. Giuliani S, Grano C, Aminoff D et al (2017) ARM-Net consortium, transition of care in patients with anorectal malformations: consensus by the ARM-Net consortium. J Pediatr Surg 52(11):1866-1867

Publisher's Note Springer Nature remains neutral with regard to jurisdictional claims in published maps and institutional affiliations. 